\title{
Understanding the Policy Context for Supporting Students with Psychiatric Disabilities in Higher Education
}

\author{
Mary Elizabeth Collins, Ph.D. \\ Carol T. Mowbray, Ph.D.
}

\begin{abstract}
Interest in postsecondary education for persons with psychiatric disabilities is high among consumers and advocates. However, the existence of program supports for higher educational goals is very uneven across U.S. states. This study was designed to examine the policy context in which states and educational institutions address needs of individuals with psychiatric disabilities to attend and succeed in postsecondary education. In 10 selected states, telephone interviews were conducted with key informants in state agencies of mental health, vocational rehabilitation, and higher education, as well as representatives of state-level advocacy organizations. Additionally, a search of websites relevant to state policy was conducted. The findings identify factors that facilitate and inhibit the development of policy and programs supportive of students with psychiatric disabilities. Facilitating factors include a strong community college system, progressive philosophy of the state mental health agency, and interest of consumers and the advocacy community. Inhibiting factors include political and budgetary uncertainty, competing priorities in the mental health system, emphasis on a medical rather than rehabilitative model, regulations of the VR system, and lukewarm enthusiasm of the advocacy community. Implications for community mental health services are included, particularly related to further policy development in support of students with psychiatric disabilities.
\end{abstract}

KEY WORDS: psychiatric rehabilitation; mental health policy; post-secondary education.

Mary Elizabeth Collins is Associate Professor at the Boston University School of Social Work.Carol T. Mowbray is Professor at the University of Michigan School of Social Work.

This study was supported by a Grant from the Spencer Foundation Small Grants Program.

Address correspondence to Mary Elizabeth Collins, Ph.D., 264 Bay State Road, Boston, MA, 02215; e-mail: mcollins@bu.edu. 


\section{INTRODUCTION}

People with psychiatric disabilities are frequently unable to secure the economic and social benefits of higher education (Jayakody, Danziger, $\&$ Kessler, 1998). Because the onset of mental illness typically occurs during young adult years (Beiser, Erickson, \& Fleming, 1993), efforts to achieve higher education are often disrupted. The educational potential of individuals who experience mental illness has been documented; the median educational level for this population is over 12 years and 20-50\% has some college experience (Hazel, Herman, \& Mowbray, 1991; Tessler \& Goldman, 1982; Unger \& Anthony, 1984). With contemporary developments in psychotropic medications and effective psychiatric rehabilitation methods, more and more individuals with serious psychiatric disorders are likely to pursue goals such as attaining higher education (Haefner \& Maurer, 2000).

Although a fairly new area of study, research is beginning to accumulate on the higher education experiences of persons with psychiatric disabilities. One set of studies has surveyed students, supportive services personnel, and faculty and administrators to understand the experience of the psychiatrically disabled population in college (Enright, Conyers, \& Syzmanski, 1996; Stanley \& Manthorpe, 2001; Weiner \& Wiener, 1996). As a whole, this body of research has documented the continuing presence of these students on college campuses despite ongoing stigma within the educational environment. Although disability support services can play a key role in helping students with disabilities access and remain in higher education (Enright et al., 1996), research indicates that even when these services are available, students with psychiatric disabilities continue to experience educational barriers (Szymanski, Hewitt, Watson, \& Swett, 1999). In the largest institutional study on this topic that has been reported, we (Collins \& Mowbray, 2005) conducted a survey of disability services offices in 275 colleges and universities located in 10 states. Among the key findings were the generally positive attitudes towards serving students with psychiatric disabilities, the wide variation among disability services offices (organization, services provided, clients served), and the continuing barriers for students to access these services.

Another set of studies on the experiences of students with mental illnesses has focused on the development, implementation, and evaluation of programs to support these students in completing their education goals. In a comprehensive review of the research on Supported Education programs, Mowbray and Collins (2002) reviewed findings 
from 11 studies and summarized the data on the characteristics of participants, program implementation issues, and outcome attainment. Summarizing the evidence, we concluded that the effectiveness data "confirm[ed] the positive outcomes for supported education programs in many different settings, with different model variations, and for different client subgroups (p. 192)."

Currently lacking from the research literature is an understanding of the policy context in which colleges and universities address the needs of students with psychiatric disabilities. Although federal policy (Section 504 of the Rehabilitation Act of 1973 [P.L. 93-112] and the Americans with Disabilities Act [P.L. 101-336]) is in place to guarantee the rights of students with psychiatric disabilities, this population remains underrepresented on college and university campuses. The specific reasons for uneven implementation are unknown but likely include variations in state legislation and/or local policy implementation, availability of supportive programming, and the state and institutional history and contemporary advocacy for disability rights. As Bateman (1997) has noted, most efforts to support students with psychiatric disabilities in college are based on the independent efforts of postsecondary institutions and providers of rehabilitation services. There is little research on the systematic development of statewide efforts that would allow for a more integrated approach. This article reports a study that was designed to examine the policy context supporting or inhibiting access to or retention of persons with psychiatric disability in higher education.

\section{THEORETICAL FRAMEWORK}

To investigate the policy context that influences the responses of educational institutions to students with psychiatric disabilities, our inquiry utilized the theoretical framework of the new institutionalism (DiMaggio \& Powell, 1983, 1991) to examine differences across postsecondary institutions. This framework posits a tendency for organizations to persist rather than change, to conform to the larger field (i.e., higher education) rather than innovate, and to become increasingly homogenous to similar organizations (DiMaggio \& Powell, 1991). While the tendency is for institutional arrangements to preclude choices regarding course of action, thereby leading to organizational inertia (DiMaggio \& Powell, 1983), some studies have identified educational institutions' adaptations to technical and political environments (e.g., Kraatz \& Zajac, 1996). DiMaggio and Powell (1983) identified three 
processes (coercive, mimetic, and normative) that impact variation in institutional responses. From these processes, we chose to focus on coercive processes (laws/statutes, efforts of the advocacy community, legal precedents), since these were most relevant at the state level-the focus of our study.

\section{METHODS}

\section{Sample Selection}

An earlier study identified existing Supported Education programs in each of the 50 states. Using this information we selected five states that had three or more Supported Education programs and identified a similar state (geographic area and population size) with no known Supported Education programming. Our assumption was that having three or more Supported Education programs was an indicator of some forces within the state that had been successful in achieving programming supports for persons with psychiatric disability to attend higher education. The matched states were then selected to achieve variation on this dimension. The selected states with known SE programs included: Massachusetts, Michigan, North Carolina, Utah, and California. Additional states in the sample included: Maryland, Indiana, Georgia, Iowa, and Oregon. Potential interview respondents were identified by searching the official state website for each of the 10 states and identifying key personnel in the Departments of Mental Health, Rehabilitative Services, and Higher Education. Additionally, websites of the National Mental Health Association (NMHA) and the National Alliance for the Mentally Ill (NAMI) were examined to find state affiliates in each of the 10 study states. Letters explaining the study were sent to the Commissioner, Administrator, or Director of each of the three state agencies (or the most relevant division if identified on the website) and the Executive Director of the state affiliates of NMHA or NAMI. Letters were sent to 40 identified people and were followed up with email and phone contacts to request interviews. In most cases, the originally identified person provided a referral to someone else in the agency with specific expertise on the issues. A total of 22 people were interviewed. Non-participation was due to agency policy not to participate in research $(n=2)$, too busy $(n=2)$, issue not on their agenda/nothing to say about it $(n=2)$, could not be scheduled after repeated attempts and were considered to be passive refusals $(n=12)$. Table 1 identifies the number contacted and interviewed by state.

\section{Data Collection Procedures}

When agreement to participate in the interview was obtained, a half hour phone interview was scheduled. A semi-structured interview guide was used to collect data on: history of postsecondary education, disability, and mental health policy within the state; historical or current legal challenges regarding persons with disabilities and access to education; existence of formal, ongoing resources/supports for persons with psychiatric disabilities to attend postsecondary institutions (e.g., Supported Education programs); eligibility for educational financial aid; interaction of employment and education policy for those 


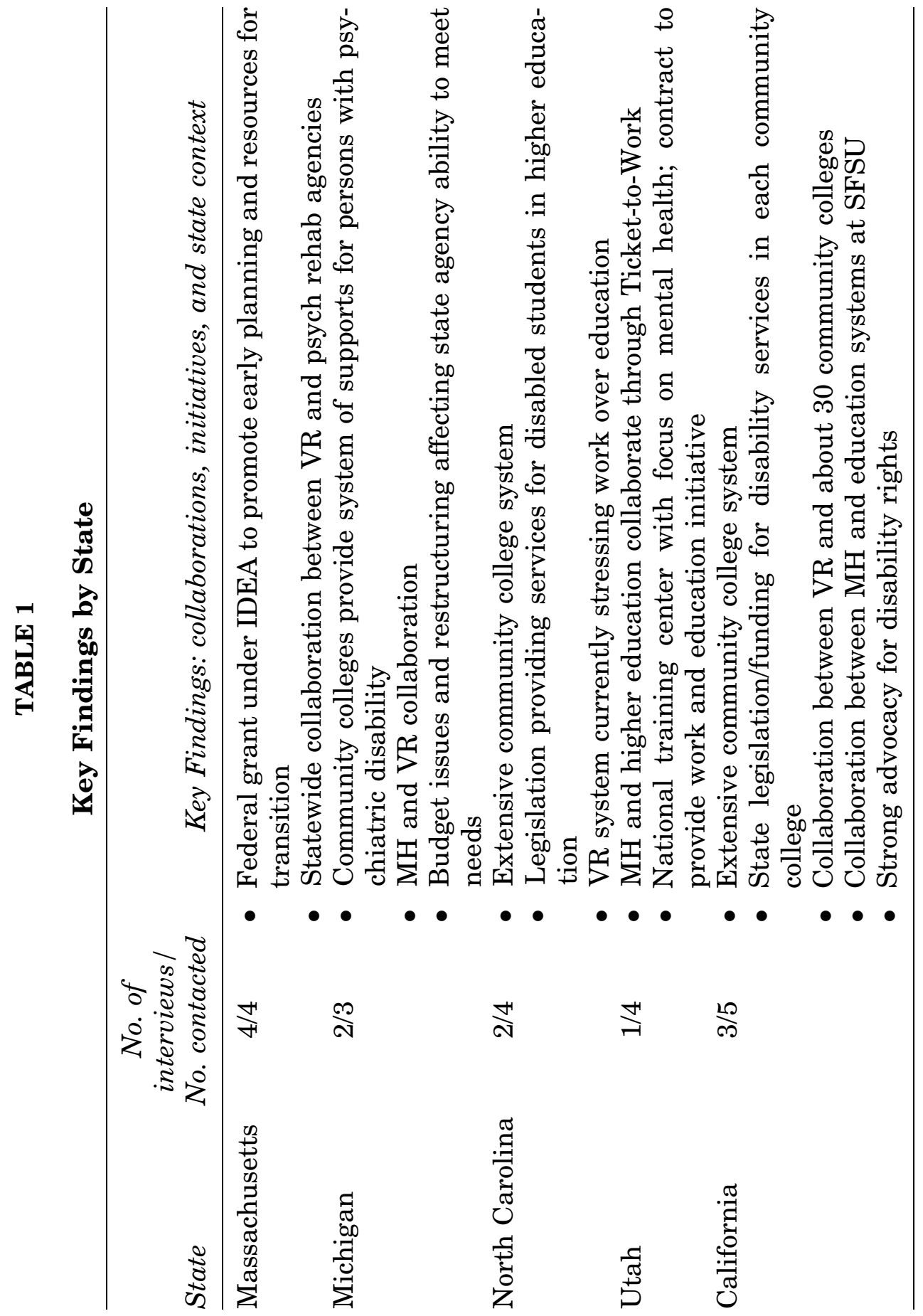




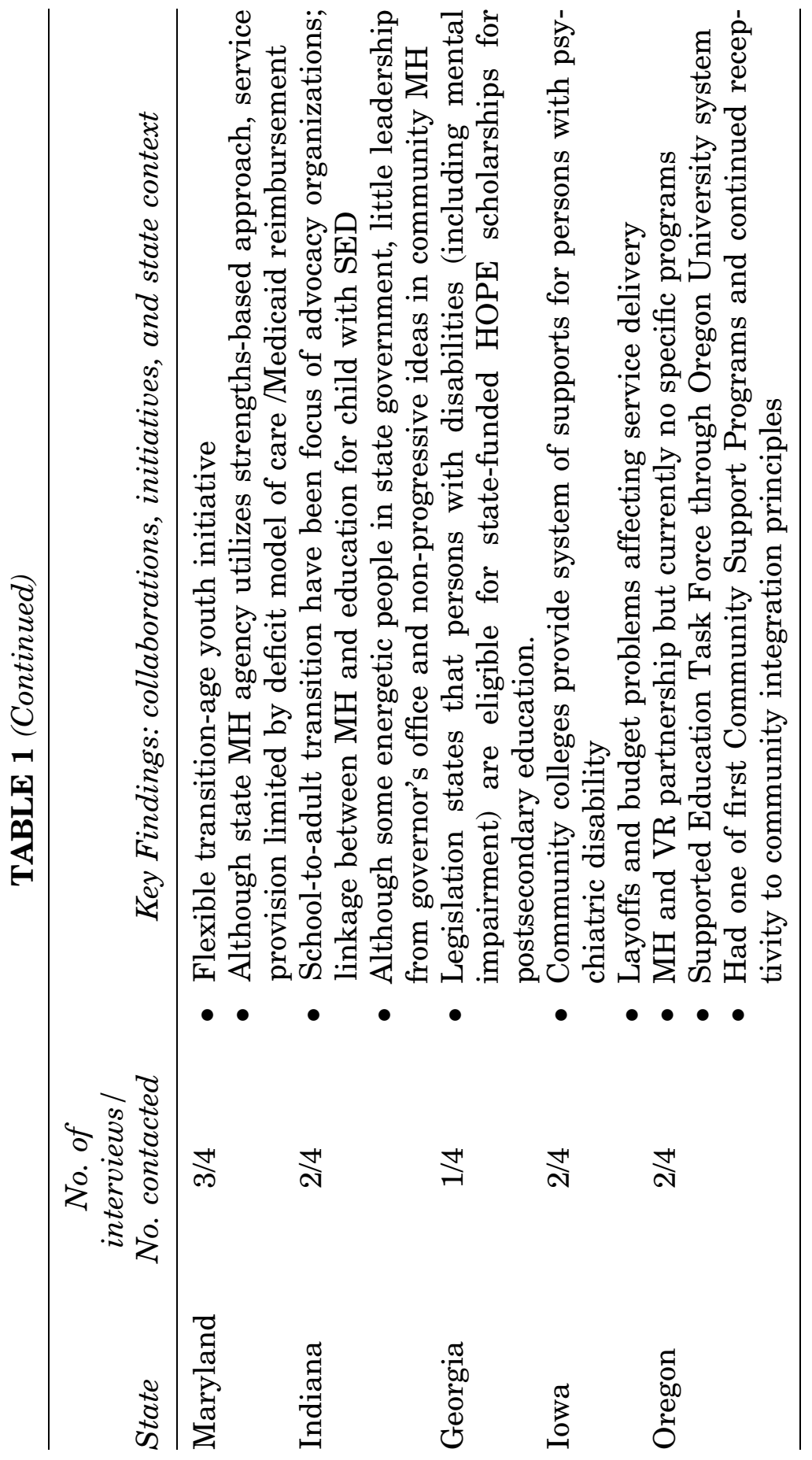


receiving Social Security Disability Insurance/Supplemental Security Income; and the visibility and perceived impact of the disability/mental health advocacy community.

To provide an independent check on policy information collected through the telephone interviews, we searched for formal legislative state policy via state government website search engines and other websites that compile state policy developments (e.g., the National Conference of State Legislatures [ncsl.org], the National Governors Association [nga.org]).

\section{Data Analysis Plan}

Handwritten interview notes were organized by question and content analysis within each question was conducted to identify themes. Of particular interest were innovations within each state and perceptions of respondents regarding either facilitators or inhibitors to policy development within the state. The text of the notes was examined to identify these themes. For example, types of facilitators and barriers were grouped based on respondents' answers to the questions on the interview guide. Content analysis was also conducted of written state policy found on state websites. Because there was very little state policy development and the description of the policies was very concrete, this analysis simply identified the substance of the policy (e.g., financial aid).

\section{RESULTS}

\section{Federal Policy Context}

Key federal policies that were relevant to state operations include: the Americans with Disabilities Act, the Rehabilitation Act of 1973, Social Security's Ticket-to-Work program, and the Individuals with Disabilities Education Act (IDEA). The Americans with Disabilities Act (ADA) (P.L. 101-336) is the most comprehensive civil rights legislation to prohibit discrimination against people with disabilities. Public and private businesses, state and local government agencies, private entities offering public accommodations and services, transportation, and utilities are required to comply with the law. This includes institutions of higher education.

Section 504 of the Rehabilitation Act of 1973 states that, "No otherwise qualified person with a disability in the United States... shall, solely by reason of... disability, be denied the benefits of, be excluded from participation in, or be subjected to discrimination under any program or activity receiving federal financial assistance." Colleges and universities that receive federal financial assistance must not discriminate in the recruitment, admission, or treatment of students. Postsecondary institutions must make changes, when appropriate, to ensure that the academic program is accessible, to the greatest extent 
possible, by all students with disabilities. Additionally, the Rehabilitation Act of 1973, as amended, authorizes the allocation of federal funds for the administration and operation of a vocational rehabilitation (VR) program to assist individuals with disabilities in preparing for and engaging in gainful employment.

Ticket to Work and the Work Incentives Improvement Act of 1999 are designed to provide people with disabilities more choices and opportunities when attempting to go to work. The program provides a "ticket" to disability beneficiaries that may be used to obtain VR and employment services and other support services. Anyone who receives compensation from SSDI or SSI who is between the ages of 18 and 64, and who is not expected to get better, will get a Ticket to Work.

The Individuals with Disabilities Education Act (IDEA) requires public schools to make available to all eligible children with disabilities a free appropriate public education in the least restrictive environment appropriate to their individual needs. IDEA requires public school systems to develop an appropriate Individual Education Plan (IEP) for each child. Although IDEA and its IEP provisions do not apply to postsecondary schools, transition services are available to prepare students with disabilities for adult life. This can include developing postsecondary education and career goals, getting work experience while still in school, and setting up linkages with adult service providers such as the VR agency.

\section{State Policy}

Data identifying key findings by state are found in Table 1 . None of our respondents were able to identify any formal state policies relevant to students with psychiatric disabilities. However, they were often able to provide examples of local (usually pilot) programs that were in place. These programs are described below. The search for state-specific legislation regarding higher education for persons with psychiatric disabilities confirmed there was very little, and none specific to psychiatric disabilities. Both California and North Carolina had legislation regarding services for disabled students in higher education. Georgia had legislation which clarified the eligibility of persons with disabilities (including mental impairment) for state-funded HOPE scholarships for postsecondary education. Utah had a legislative appropriation to the Center for Persons with Disabilities at Utah State University for long-term professional development programs for disability services 
personnel (training of supported employment personnel, interpreters for deafness and hearing impairments, and behavior support specialists). Other state legislation was more general (e.g., non-discrimination provisions for persons with disabilities).

\section{State-level Resources and Supports}

When formal on-going supports existed within states, these generally were one of three types: (1) supports for persons with disabilities in community college systems; (2) VR services that included postsecondary education or training for clients; and (3) youth transition services for young people with disabilities.

(1) Supports for persons with disabilities in community college systems. While all postsecondary institutions receiving federal aid are required to comply with the ADA, and thus have an identified ADA coordinator, schools and school systems can vary widely in the extent to which they provide supports to persons with disabilities. Within the states studied, the California Community College system appeared to have the most fully developed disability support service system. In 1976, the California state legislature provided funding to establish Disabled Students Program and Services (DSPS) offices within the community college system. The law provides parameters (in accord with the ADA, Section 504, and court decisions involving civil rights) as to how each college can use funding. There is no funding or requirement for particular services to persons with psychiatric disabilities, but some community colleges can and do provide special services to this population. North Carolina, too, had a large community college system and disability support services available within these colleges. Again, however, anything special regarding psychiatric disabilities was at the school level. In other states (Michigan, Iowa), informants also reported that the system of supports through their community colleges is probably the biggest support available to persons with psychiatric disabilities who desire to attend college.

Our study did not intend to focus only on supports available in community colleges. It is instructive, however, that in conducting the interviews, persons within the community college system were most often identified as the people to speak with. One respondent noted that community colleges are usually more comfortable for persons with psychiatric disabilities. In addition to supports provided by disability services offices, the campuses are smaller and the faculty is reportedly 
more attentive to individual student needs. Some respondents noted, however, that many community college systems do not have the size or infrastructure to provide as much assistance as state college or university systems. Four-year colleges and universities typically have health centers and counseling centers that can provide assistance with psychological problems, community colleges generally do not have these resources.

(2) VR services that included postsecondary education or training for clients. Respondents representing VR systems consistently reported that: (a) their rehabilitation programs consisted of postsecondary education (including college), if appropriate; (b) their work with clients is highly individualized and focused on client choice; (c) psychiatric disabilities are treated no differently (in terms of opportunities and services provided) than other disability types; and (d) financial support for postsecondary education (including college) is available for clients if this is part of their plan. One respondent reported that support for postsecondary education was related to a client's ability to perform in college (e.g., IQ, GPA). Another noted that judgment was involved as well; "counselors will work with [clients] to identify the best course of study ... more savvy counselors have attempted to determine whether someone is truly motivated." A different perspective from advocates suggested that counselors in the VR system are often more begrudging about postsecondary opportunities for persons with psychiatric disabilities than they are for persons with other types of disabilities. One respondent noted that "vocational training and assistance programs for people with mental illness encourage and usually only offer low-skill level jobs."

(3) Youth transition services for young people with disabilities. Three states, in particular, discussed transition-age services. Maryland reported a flexible transition-age youth initiative that provides discretionary funds to local providers which could be used for tuition and other supports. There are 12 projects for transition age youth in that state. One of these is specific to a local community college and student mentors are available to provide support. In Maryland, the Interagency Transition Council for Youth with Disabilities was created through legislation about five to 6 years ago. The Council includes representatives of special education, mental health, developmental disabilities, labor, and parents/family, and was designed to integrate education systems and break down barriers for youth aging out of the special education system. Although some projects were carried out, the legislation offered no additional funding to departments. Consequently, the 
projects were quite limited. Indiana and Massachusetts were the other states reporting current efforts focusing on transition services.

In these findings regarding the implementation of federal policy two things were notable. First, none of the three mechanisms identified above (supports in the community college system, VR services for postsecondary education, and transition planning services) put special emphasis on individuals with psychiatric disabilities. Although psychiatric disability was included within each of these mechanisms, specific attention to persons with psychiatric disabilities existed only occasionally through special, local projects. Second, mental health systems generally operated informally in helping persons with disabilities attend college, as compared to either community college systems (when strong) or state VR agencies (because of federal funding in this area).

\section{Collaborations Among Agencies and Institutions}

There was great variation in the organization of state departments of higher education, mental health and VR and in no case was there widespread collaboration among the three agencies concerning postsecondary education for adults with psychiatric disabilities. There were, in several cases, collaborations between two of the three departments-generally not formal or ongoing. Rather, they were characterized as episodic, occasional (e.g., interaction on a Task Force), "good working relationship," or "interpersonal rather than systemic." Most of the reported collaborations involved VR and the community college system. For example, California reported a special collaboration between VR and about 30 community colleges. In this collaboration, VR funds were used to establish more services at the community colleges related to rehabilitation and work. Although mostly not specific to psychiatric disabilities, one or two of these projects have focused on this group.

A collaboration between mental health and education systems was identified in California. The Mental Health Education and Workforce Development Initiative, affiliated with San Francisco State University, is designed to "bring together the education system and mental health system as essential partners in serving the mental health needs of the community." The Initiative has four foci: mental health/human services workforce education and training including the education of mental health clients/consumers; mental health education for mainstream teachers (preschool-postgraduate); an enhanced, comprehensive 
system of effective supports for college students with mental disabilities; and mental health education for the culturally diverse communities of the greater Bay Area (SFSU, 2002).

Mental health and VR reportedly have worked closely together in Michigan. At the state level, there have been meetings between the two entities for 6 years, minimally on a quarterly basis, to identify problem areas and new programs. Through a partnership with the Department of Community Health (of which mental health is a part), the VR program can get full federal matching funds for providing VR services and can also serve more clients including those with mental health needs. Unfortunately, respondents reported that within the state a recent reorganization of community mental health boards resulted in a reduction of services and fewer mental health consumers coming to VR.

Massachusetts also had statewide collaborative links aimed at planning and policy. A statewide program, Supported Employment and Education (SEE), contracts with approximately 20 providers of services, including clubhouse programs for psychiatric rehabilitation and community colleges. Postsecondary education is a part of, albeit not a large focus in most programs. For those clients pursuing postsecondary education, most go to school part-time; four-year college enrollment is not actively promoted. One respondent noted that there is a very real issue regarding the extent to which state mental health agencies should be involved in supporting postsecondary education and the extent to which this would harm other key functions: "we can never significantly impact the needs of the mentally ill [regarding education and employment] with our funding, it would violate our core mission." Additionally, it was noted that federal agencies could do more in the area of supporting higher education.

In Oregon, there was a reported partnership between mental health and VR but currently there were no specific programs. A few years ago there had been a state-funded training program for psychiatric technicians that included some trainees with a psychiatric disability. However, this was a pilot project and the legislature chose not to continue funding. A respondent from the community college system reported that VR works very closely with schools and that schools have an informal liaison with other state agencies. Additionally, there is a Supported Education Task Force, coordinated through the Oregon University system, which was characterized as a well-intended effort with many people involved. 
In Indiana, there was a linkage between mental health and education for children with serious emotional disturbance (SED). In Utah, mental health and higher education have collaborated through the Ticket-to-Work program and the mental health system works directly with some universities regarding Ticket-to-Work. Additionally, in Utah there is a national training center that provides focus, initiatives, and attention to issues of mental health. The training center has a contract with the state Department of Mental Health to provide a work and education initiative. While the main focus has been work, computers are available through clubhouses to aid in consumers' educational pursuits. There is an interest to develop educational initiatives through clubhouse settings, but to do so, more grant funding is needed.

\section{Facilitators to Educational Supports for People with Psychiatric Disabilities}

Interview subjects typically were able to describe some elements of state history, politics and political culture which they felt created an impact on the ability of the state to provide support for persons with psychiatric disabilities in higher education. From the interviews, several facilitating factors were identified.

Strong Community College Systems. Both California and North Carolina had well-developed community college systems. Within the California Community College system, there has been extensive development of disability support services. This was attributed to the activist nature of California and the origins of the disability rights movement in Berkeley in the 1960s (which is still considered to be strong). Although lacking the disability rights history of California, the North Carolina community college system appears to be extensive. According to respondents, the system was born in the 1960s; North Carolina wanted to be known for education and has a postsecondary school within 25 miles of every citizen.

Progressive Philosophy of State Mental Health Agency. In the late 1970s, Oregon had one of the first Community Support Programs (services, including case management, supportive housing and employment, to individuals with severe and persistent mental illness, living in the community). A number of people involved in implementing these projects have had continued involvement since that time, facilitated by the fact that Oregon is a small state. Thus, there is a lot of 
receptivity to community support and community integration principles, as well as efforts to keep abreast of new developments in the field.

Interest of the Advocacy Community. In California, the work of disability advocates was perceived as central to the development of disability support services in the community college system. These were not mental health advocates specifically, and the services provided are not specifically for persons with psychiatric disabilities. Nonetheless, the initial gains of disability advocates provided infrastructure for mental health advocates to build on within the state. In terms of mental health advocates specifically, there was no evidence of their making a cohesive push within any of the states. A few advocacy organizations, however, appeared more active in terms of educational rights. This activity was largely driven by the interests of particular members of the organization.

Interest of and Greater Capabilities of Consumers. Several respondents noted that advances in the treatment of mental illness have resulted in a population that is, overall, less severely disabled than in previous times. This development has been an impetus to the greater number of persons with mental illness who are able to attend college. Further advances are projected, resulting in more students with psychiatric disabilities succeeding at postsecondary education. A representative of an advocacy organization stated that people "aren't as sick as they used to be ... with medications and treatment they live "normal lives'." In addition to the changes in the population, several respondents noted the desire within state agencies to do better at addressing issues related to accessing higher education. A respondent from the community college system also suggested that there is agreement among colleges that students with psychiatric disabilities are a rapidly increasing population and there are many questions about how to address their needs.

\section{Barriers to Educational Supports for People with Psychiatric Disabilities}

Interview data also identified several barriers that existed within states that were perceived to limit the state's further development of supports for individuals with psychiatric disabilities in higher education. 
Political and Budgetary Uncertainty. All states reported current and impending budget crises which were impacting the delivery of state services and which precluded expansion of current spending and new initiatives. In addition to anticipated cutbacks that directly affect services and supports, these crises create an atmosphere of uncertainty that inhibits discussion of new ideas and new initiatives. Furthermore, some of the states saw a change in governorship in early 2003; this inhibited any planning until the priorities of the new governor were made known.

Some of the specific comments included the following. In North Carolina, the VR system has changed to require financial need as a criterion for educational financial assistance, and, VR now (because of budget mandates) is stressing work instead of education. In Michigan, the budget is also tight, resulting in early staff retirements at VR and at the Department of Community Health (which includes mental health programming). In addition, the Department of Community Health is currently restructuring, there is a new governor, and "in the past psychosocial interventions have been only partly successful." In Iowa, layoffs were also experienced and the budget, as reported by a respondent from the educational system, is in "an all-time crisis." Furthermore, it was noted that the first people to lose services are low income, resource-intensive people; "even during times of affluence it is difficult to get support for persons with disabilities, especially if the disability is not visible." Although a VR respondent stated this to be an area in which "we would like to do a better job," neither specialized staff nor the resources were available to focus specifically on education. An Indiana respondent reported some energetic people in state government (mental health and VR), interested in cutting edge ideas, who view people in more holistic terms. In the community mental health area, however, there are not strong and progressive leaders. Also, there was reportedly no leadership from the governor's office on this issue. Moreover, according to one respondent, "... no governor's future has been based on a strong mental health system."

Competing Priorities in Mental Health Systems. Mental health systems seem to be particularly vulnerable in the current climate of economic uncertainty. The key barriers within the mental health system appear to be resource constraints and lack of agreement about the importance of higher education supports given the context of the many other needs of the population. Moreover, one respondent opined that a fundamental lack of adequately covered health and mental health care 
contributes to problems in education, training, and employment. Persons with mental illness, because of its recurring nature, cannot risk losing Medicaid when they become employed. Consequently, a VR counselor "can't in good conscience tell clients to leave health insurance for work... [i]f we could solve health insurance successfully we could do more to help this population."

Emphasis on a Medical Model of Care vs. a Rehabilitative Model. Respondents in two states noted the limitations imposed by financing mental health services through Medicaid. One state reported that there has been a fairly rich benefit package for people with mental illnesses. Yet, the push for reimbursement through Medicaid has led to an increasing medical approach to services' access and authorization. Thus, while the mental health agency views mental health issues from a strengths-oriented, rehabilitation perspective, the reality of Medicaid reimbursement limits possibilities for service provision. Reportedly, this means that the system is based on deficits, with little emphasis on issues like education. Respondents in Indiana reported some strengths regarding mental health services. Nonetheless, as a politically conservative state, the development of a progressive mental health service system integrating rehabilitation programming had not transpired; the system continued to operate within a medical model.

VR System and its Regulations. A representative of one state-level advocacy group described the VR system as a barrier. Although the respondent identified VR as a willing collaborator (e.g., representatives were willing to come to meetings, talk with consumers, explain laws and eligibility), she also described the system as frustrating for families to access and not understanding of mental health needs. A representative of an advocacy organization in another state noted that although VR can fund up to a Bachelor's degree or other job training, cheaper job training is easier to get. Some respondents voiced perceptions that the number of people in college is declining because of funding. Many respondents were queried specifically about work incentives and requirements that may be related to SSI or SSDI receipt and agreed that the emphasis on work, rather than education, is another barrier endemic to the system.

Advocacy Organizations. Most mental health advocacy organizations have an agenda broader than that of supporting persons with mental illness in obtaining postsecondary education. Several advocacy 
organizations declined participation in the interview because the issue of postsecondary education was not an organizational priority. From the data collected, it appeared that the advocacy community was, in general, supportive but not active in promoting mechanisms for persons with psychiatric disabilities to enter and succeed in postsecondary education. The limited attention to higher education issues was attributed to these organizations' more active commitment to basic rights such as medical and mental health treatment, housing, and appropriate medication. Occasional concern was expressed by members of mental health advocacy organizations that attention to educational issues was inappropriate, since a fight for more basic rights and assistance was still needed.

\section{IMPLICATIONS FOR COMMUNITY MENTAL HEALTH SERVICES}

The right to higher education for students with disabilities is undisputed. Evidence from this study and other research suggests that an increasing number of students with psychiatric disabilities are pursuing higher education. States did not have specific policies to address issues of persons with psychiatric disabilities in higher education. Rather, the focus of states was the implementation of federal policies. Any special initiatives were primarily local rather than statewide and tended to involve VR and educational systems more than mental health. Moreover, collaborations were not widespread and tended to be between individuals and groups rather than be systemically oriented. Federal funding appeared to be critical to the provision of higher education support services to students with disabilities. This is particularly true within the current economic climate. Neither the mental health advocacy community nor state mental health systems were committed to providing educational supports to adults with mental illness. Although they were not opposed to the concept, their concerns regarding competing needs of the mentally ill population (e.g., access to basic health and mental health care) led to weak support for higher education pursuits.

There are several implications of the findings for mental health services, particularly within federal policy, state government, and advocacy organizations. Federal funding (most notably though VR) has been used in a variety of ways (often pilot projects) to support students with psychiatric disabilities in pursuing higher education. Continued and expanded federal funding may therefore be needed for states to 
implement the types of supports that ensure the rights of students with psychiatric disabilities to attain their educational goals. Protection of the fundamental rights of students with disabilities to access higher education is a responsibility of the federal government; for some individuals these rights cannot be secured without appropriate support. Funding for disability services offices, special initiatives for psychiatrically disabled students and federal financial aid are needed to assist these students.

In recent years, national policy (e.g., most notably TANF but also public housing and other segments) has predominantly emphasized work-focused programming to the virtual exclusion of assistance for educational attainment. Overall, this policy seems short-sighted, ignoring the developmental potential of many segments of the population. Similarly, this perspective neglects that higher education is necessary to obtain stable jobs with benefits and a living wage. More progressive VR systems have attempted to address the developmental potential and long-term productivity of clients but operate within organizational constraints well-known to state agencies. These include the pressure to close cases, high caseloads per worker, targeting more easy-to-serve clients and sanctioning clients with greater needs (Lipsky, 1980).

Within state government there was little resistance to the idea of supporting persons with psychiatric disabilities in pursuing higher education. Individuals in state government, however, are cognizant of constraints in developing new supports when under pressure to cut budgets, programs, and staff. Creativity, establishment of collaborations, and federal funding are needed to develop these supports within existing constraints. There are several methods by which educational supports for persons with mental illness can be implemented. Supports can be attached to mental health programming, VR programming, higher education services, or transition services for young people in the K-12 system.

There was wide variation in the extent to which the relevant systems were considered progressive. There was evidence in most states that the mental health system was not keeping pace with new thinking about services for individuals with mental illness; specifically, the shift from a medical model of care to one which promotes community supports via a psychosocial rehabilitation model. Further development of mental health systems of care is needed to facilitate the formation of postsecondary supports.

When efforts are coordinated and sustained, advocates can have great impact on both federal and state policy, even during times of 
resource constraint. Given the progress in mental health treatments, there is likely to be increasing attention to postsecondary education. Stigma continues to be a barrier to higher education in several ways (student reluctance to identify themselves to disability services, inaccurate media portrayals of persons with mental illness, less acceptance of persons with psychiatric disabilities than those with physical or sensory impairments, etc.). The advocacy community will continue to be instrumental in fighting the stigma that discourages persons with mental illness from succeeding in college environments.

\section{CONCLUSION}

Providing appropriate supports for persons with psychiatric disabilities to attend and succeed in higher education institutions requires the combined efforts of several state agencies (education, mental health, VR), levels of government (federal, state, local), and advocacy organizations. This research has identified some of the current efforts within each of these entities and has also identified the challenges that are encountered. Further developments in the field of mental health services, such as those suggested above, are needed to insure the rights of students with psychiatric disabilities and to secure the societal benefits resulting from development of the full talents of these individuals.

\section{REFERENCES}

Bateman, M. (1997). The development of a statewide supported education program: Assessing consumer and family needs. Psychiatric Rehabilitation Journal, 21, 16-22.

Beiser, M., Erickson, D., \& Fleming, J., (1993). Establishing the onset of psychotic illness. American Journal of Psychiatry, 150, 1349-1354.

Collins, M.E. \& Mowbray, C.T. (2005). Higher education and psychiatric disabilities: National survey of campus disability services. American Journal of Orthopsychiatry 75(2), 304-315.

DiMaggio, P. J., \& Powell, W. W. (1983). The Iron Cage revisited: Institutional isomorphism and collective rationality in organizational fields. American Sociological Review, 48, 147-60.

DiMaggio, P. J., \& Powell, W. W. (1991). Introduction. In W. W. Powell, \& P. J. DiMaggio (Eds.), The new institutionalism in organizational analysisUniversity of Chicago Press, Chicago, IL.

Enright, M. S., Conyers, L., \& Szymanski, E. M. (1996). Career and career-related educational concerns for college students with disabilities: An overview of legislation, theory, and research. Journal of Counseling and Development, 75, 103-114.

Haefner, H., \& Maurer K. (2000). The early course of schizophrenia: New concepts for early intervention. in: Unmet need in psychiatry: Problems, resources, responses. New York, NY: Cambridge University Press.

Hazel, K., Herman, S. E., \& Mowbray, C. T. (1991). Characteristics of adults with serious mental illness in a public mental health system. Hospital and Community Psychiatry, 42, 518-525. 
Jayakody, R., Danziger, S., \& Kessler, R. (1998). Psychiatric disorders and socioeconomic status. Social Science Research, 27, 371-387.

Kraatz, M. S., \& Zajac, E. J. (1996). Exploring the limits of the new institutionalism: The causes and consequences of illegitimate organizational change. American Sociological Review, 61, 812-836.

Lipsky, M. (1980). Street-level bureaucracy: dilemmas of the Individual in Public Services, New York: Russell Sage Foundation.

Mowbray, C. T., \& Collins, M. (2002). The effectiveness of supported education: Current research findings. In C. T. Mowbray, K. S. Brown, K. Furlong-Norman, \& A. S. Soydan (Eds.), Supported education and psychiatric rehabilitation: Models and methodsInternational Association of Psychosocial Rehabilitation Services, Linthicum, MD.

San Francisco State University. (2002). Draft proposal for the mental health education and workforce development initiative.

Stanley, N., \& Manthorpe, J. (2001). Responding to students' mental health needs: Impermeable systems and diverse users. Journal of Mental Health, 10, 41-52.

Szymanski, E. M., Hewitt, G. J., Watson, E. A., \& Swett, E. A. (1999). Faculty and instructor perception of disability support services and student communication. CDEI, 22, 117-128.

Tessler, R. C., \& Goldman, H. H. (1982). The chronically mentally ill: Accessing community support programs, Cambridge, MA: Balinger.

Unger, K., \& Anthony, W. (1984). Are families satisfied with services to young adult chronic patients? A recent survey and proposed alternative. In B. Pepper, \& H. Ryglewicz (Eds.), The Young Adult Chronic Patient RevisitedJossey Bass, San Francisco, CA.

Weiner, E., \& Wiener, J. (1996). Concerns and needs of university students with psychiatric disabilities. Journal of Postsecondary Education and Disability, 12, 2-9. 